\title{
Histamine Turnover in the Rat Hypothalamic Nuclei Estimated from a-Fluoromethylhistidine-Induced Histamine Decrease
}

\author{
Yoshinori ITOH, Ryozo OISHI, Masahiro NISHIBORI \\ and Kiyomi SAEKI* \\ Department of Pharmacology. Okayama IIniversity Medical School. \\ 2-5-1 Shikata-cho, Okayama 700. Japan \\ Accepted October 5, 1989
}

\begin{abstract}
The turnover rates, rate constants and half-life values of neuronal histamine (HA) in 10 nuclei of the rat hypothalamus were estimated from the depletion of $H A$ induced by $\alpha$-fluoromethylhistidine ( $\alpha-F M H: 100 \mathrm{mg} / \mathrm{kg}$. i.p.), a specific inhibitor of histidine decarboxylase, on the presumption that $\alpha-\mathrm{FMH}$ depletable HA pools represent neuronal ones. Marked variation in the HA turnover rates were observed among the hypothalamic nuclei. ranging from 5.7 to $19.5 \mathrm{pmole} / \mathrm{mg}$ protein/hr.
\end{abstract}

Histamine (HA) is a putative neurotransmitter in the mammalian brain (1). Immunohistochemical evidence (2) has demonstrated that the perikarya of histaminergic neurons localized in the posterior part of the hypothalamus give rise to fibers which are widely but unevenly distributed throughout the brain. The hypothalamus contains the highest density of histaminergic fibers (2). Both the concentration and turnover rate of $\mathrm{HA}$ are also highest in the hypothalamus $(3,4)$. Although the regional distribution of $\mathrm{HA}$ within the rat hypothalamus has been reported (5). there has been no study on the HA turnover rates in discrete hypothalamic nuclei.

Although the precise physiological roles of histaminergic neurons remain to be clarified. intracerebrally injected $\mathrm{HA}$ causes changes in a number of hypothalamic functions (6) such as hormone secretion, food and water intake. regulation of body temperature and sleepwakefulness. In light of these effects of exogenously administered HA, the determination of HA turnover rates in the individual hypotha!amic nuclei seems to be of value in the search for the functional significance of histaminergic neurons. Recently, we estimated HA turnover rates in the hypothalamic nuclei of rats, on the basis of the rate of ac-

\footnotetext{
- To whom all correspondence should be addressed.
}

cumulation of te/e-methylhistamine (t-MH), a predominant metabolite of brain $H A$, after pargyline treatment (7). However, there was no information about the parameters determinings $H A$ turnover time such as the rate constant and half-life in the individual nuclei.

In the present study, we measured the rate of $\mathrm{HA}$ depletion by $\alpha$-fluoromethylhistidine $(\alpha-\mathrm{FMH})$, an inhibitor of histidine decarboxylase (8), for the estimation of the turnover rate, rate constant and half-life of neuronal HA in 10 nuclei of the rat hypothalamus.

Male Wistar rats weighing $250-300 \mathrm{~g}$ (Seiwa Experimental Animals, Fukuoka, Japan) were used. They were housed in groups in a room controlled at $22 \pm 1^{\circ} \mathrm{C}$ and maintained in an alternating $12 \mathrm{-hr}$ light/dark cycle (lights on at $06.00 \mathrm{hr}$ ). Experiments were performed between 12.00 and $15.00 \mathrm{hr}$. Rats were decapitated, and the brains were quickly removed and immersed in ice cold saline. The brains were frozen in a freezer at $-40^{\circ} \mathrm{C}$ and cut into serial frontal sections, $300-\mu \mathrm{m}$ thick. in a cryostat maintained at $-20^{\circ} \mathrm{C}$, starting at the level of the anterior commissure. Hypothalamic nuclei were removed from the frozen sections using a needle $(500-\mu \mathrm{m}$ inside diameter), according to the method of Palkovits et al. (9). The tissue HA was determined by the method of Yamatodani et 
al. (10) with modifications, using high performance liquid chromatography with fluorescence detection. This method is highly sensitive, and it enables the detection of $3 \mathrm{pg}$ of $\mathrm{HA}$. Briefly, the tissues were homogenized with $100 \mu$ of $0.2 \mathrm{M}$ perchloric acid using an ultrasonic disruptor (UP-200, Tomy Seiko, Osaka, Japan) and centrifuged at $10,000 \times \mathrm{g}$ for $30 \mathrm{~min}$ at $4^{\circ} \mathrm{C}$. An $50-\mu \mathrm{l}$ aliquot of the supernatant was directly injected into the HPLC. The system was composed of four pumps (CCPM, Toyo Soda, Tokyo, Japan) serving to independently deliver the mobile phase or reagents, a stainless steel guard column $(50 \times 4.0 \mathrm{~mm}$ inside diameter) packed with Nucleosil C18 (5- $\mu \mathrm{m}$ spherical form; Chemco Scientific, Osaka, Japan), a stainless steel separation column $(150 \times 4.0 \mathrm{~mm}$, inside diameter) packed with cation exchange resin (SP-2SW. 5- $\mu$ m spherical form; Toyo Soda). a thermostatic reactor (RE 8010, Toyo Soda) and a fluorescence spectromonitor (RF-535. Shimadzu, Kyoto, Japan). The eluate from the separation column with $0.25 \mathrm{M}$ potassium dihydrogen phosphate $(0.6 \mathrm{ml} / \mathrm{min})$ was mixed with $3.5 \mathrm{M}$ sodium hydroxide $(0.13$ $\mathrm{ml} / \mathrm{min}$ ) and $0.1 \%$ o-phthalaldehyde $(0.14$ $\mathrm{ml} / \mathrm{min})$ in a coil of teflon tubing $(5 \mathrm{~m} \times 0.25$ $\mathrm{mm}$, inside diameter) at $50^{\circ} \mathrm{C}$ to form fluorescent derivatives of $\mathrm{HA}$ with $\mathrm{O}$-phthalaldehyde, and then $4 \mathrm{M}$ phosphoric acid $(0.18$ $\mathrm{ml} / \mathrm{min}$ ) was added to the reaction product via another teflon tube ( $2 \mathrm{~m} \times 0.25 \mathrm{~mm}$, inside diameter) to stop the reaction. The fluorescence intensity was measured at an excitation wavelength of $350 \mathrm{~nm}$ and at an emission wavelength of $450 \mathrm{~nm}$. The HA turnover rate was estimated from the rate of HA depletion after the injection of $\alpha-F M H(100 \mathrm{mg} / \mathrm{kg}$, i.p.). Since maximal HA depletion was observed 2-4 hr after the $\alpha-\mathrm{FMH}$ injection (11), the remaining HA was assumed to be in non-neuronal pools, such as mast cells. On the assumption that the non-neuronal HA levels were equal, we estimated the levels of putative neuronal $\mathrm{HA}$ in each nucleus at 0 . 45 and $90 \mathrm{~min}$ after $\alpha-\mathrm{FMH}$ injection by subtracting the mean $H A$ values in the corresponding nuclei of the group treated with $\alpha$-FMH $4 \mathrm{hr}$ before. The protein content in each tissue was determined by the method of Lowry et al. (12), using bovine serum albumin as the standard.

As shown in Table 1, the HA concentration in each nucleus of the rat hypothalamus was generally consistent with previous values obtained by radioenzymatic assay (5). The HA concentration was generally higher in the posterior region (nuclei premammillaris ventralis and posterior) than in the anterior region (nuclei suprachiasmaticus, supraopticus, preopticus medialis and anterior). The percentage of neuronal $\mathrm{HA}$ in the rat hypothalamic nuclei determined in the present experiment varied between 30.1 and 55.6. From the amounts of neuronal $\mathrm{HA}$ remaining at 0.45 and $90 \mathrm{~min}$ after $\alpha$ FMH injection. which are shown in parentheses in Table 1 , the rate constant (k) for the $\mathrm{HA}$ depletion in each nucleus was calculated. The half-life values for neuronal HA calculated as $0.693 / \mathrm{k}$ were between 40 and $68.2 \mathrm{~min}$. which were compatible with the previously described value in the rat whole hypothalamus (56.6 min) (4). The HA turnover rate ( $k \times$ initial level of neuronal HA) in each nucleus varied between 5.7 (nucleus lateralis) and $19.3 \mathrm{pmole} / \mathrm{mg}$ protein $/ \mathrm{hr}$ (nucleus premammillaris ventralis). The HA turnover rates obtained in the present experiment were generally consistent with those reported previously (7).

In the mammalian brain, subcellular localization of HA shows multi-compartmental character (13): and in the rat hypothalamus, a substantial amount of HA is derived from non-neuronal tissues, such as mast cells (4). However, at present, there is no indisputable method available for kinetically distinguishing $\mathrm{HA}$ in different compartments. HA in the brain is metabolized almost exclusively by $\mathrm{HA}-\mathrm{N}$-methyltransferase to $\mathrm{t}-\mathrm{MH}$ (14), which is further deaminated by monoamine oxidase to tele-methylimidazoleacetic acid (15). The $\mathrm{t}-\mathrm{MH}$ levels exhibit a linear increase for a few hours after the injection of pargyline $(3,4)$. In rats pretreated with $\alpha-F M H(50 \mathrm{mg} / \mathrm{kg}$ ) $4 \mathrm{hr}$ prior to pargyline injection, only a small accumulation of brain t-MH occurs (4). suggesting that neuronal HA has been almost completely depleted. Therefore, in the present experiment, we measured the levels of neuronal $H A$, by adopting the assumption that the HA levels in rats treated with $\alpha$-FMH 


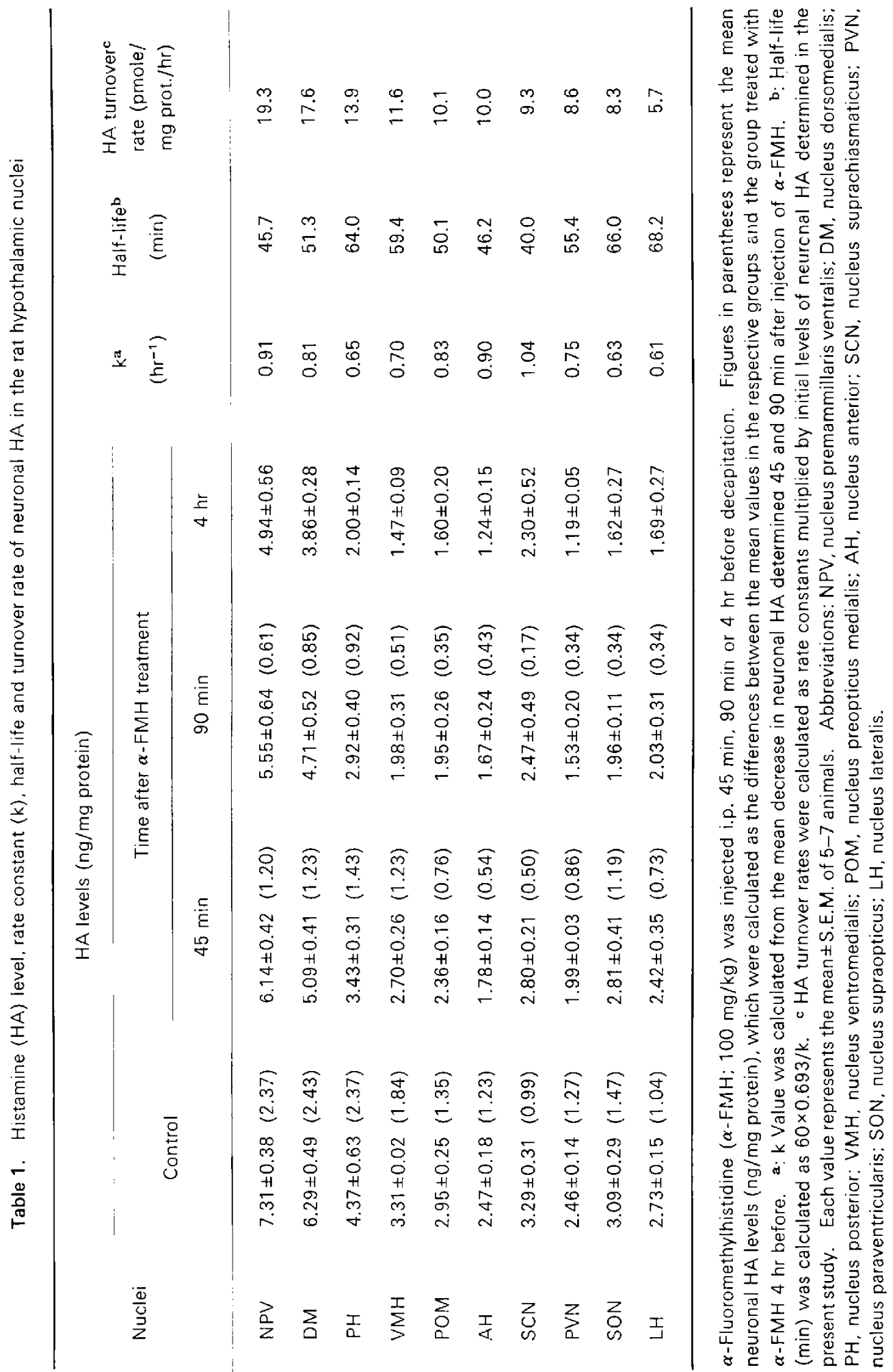


$4 \mathrm{hr}$ before represent the levels of nonneuronal HA. High HA turnover rates were observed in the nuclei premammillaris ventralis and dorsomedialis, in which both histaminergic cell bodies and fibers are present as demonstrated by immunohistochemical studies (2). Therefore, it is likely that the HA turnover rates are high in regions containing histaminergic cell bodies. On the other hand, the rate constant or half-life of neuronal HA was not markedly different among various hypothalamic nuclei.

Acknowledgment: This work was supported by a Grant-in-Aid for Encouragement of Young Scientists, 01772038. from the Ministry of Education. Science and Culture, Japan.

\section{References}

1 Schwartz, J.C., Pollard, H. and Quach, T.T.: Histamine as a neurotransmitter in mammalian brain: neurochemical evidence. J. Neurochem. 35, 26-33 (1980)

2 Watanabe, T., Taguchi, Y., Shiosaka, S., Tanaka, J., Kubota, H., Terano, Y., Tohyama, M. and Wada, $H_{\text {: }}$ : Distribution of the histaminergic neuron system in the central nervous system of rats; A fluorescent immunohistochemical analysis with histiaine decarboxylase as a marker. Brain Res. 295, 13-25 (1984)

3 Hough, L.B., Khandelwal, J.K. and Green, J.P.: Histamine turnover in regions of rat brain. Brain Res. 291, 103-109 (1984)

4 Oishi, R., Nishibori, M. and Saeki, K.: Regional differences in the turnover of neuronal histamine in the rat brain. Life Sci. 34, 691-699 (1984)

5 Pollard, H., Bischoff, S., Llorens-Cortes, C. and Schwartz, J.C.: Histidine decarboxylase and histamine in discrete nuclei of rat hypothalamus and the evidence for mast-cells in the median eminence. Brain Res. 118, 509-513 (1976)

6 Roberts, F. and Calcutt, C.R.: Histamine and the hypothalamus. Neuroscience 9, 721-.739 (1983)

7 Itoh, Y., Oishi, R., Nishibori, M. and Saeki, K.:
tele-Methylhistamine levels and histamine turnover in nuclei of the rat hypothalamus and amygdala. J. Neurochem. 53, 844-848 (1989)

8 Kollonitsch, J., Patchett, A.A., Marburg, S., Maycock, A.L., Perkins, L.M., Doldouras, G.A., Duggan, D.E. and Aster, S.D.: Selective inhibitors of biosynthesis of arninergic neurotransmitters. Nature 274, 906-908 (1978)

9 Palkovits, M., Brownstein, M., Saavedra, J.M. and Axelrod, J.: Norepinephrine and dopamine content of hypothalamic nuclei of the rat. Brain Res. 77, 137-149 (1974)

10 Yamatodani, A., Fukuda, H., Wada, H., Iwaeda, T. and Watanabe, T.: High-performance liquid chromatographic determination of plasma and brain histamine without previous purification of biological samples: cation-exchange chromatography coupled with post-column derivatization fluorometry. J. Chromatogr. 344, 115-123 (1985)

11 Maeyama, K., Watanabe, T., Taguchi, Y., Yamatodani, A. and Wada, H.: Effect of $\alpha$ fluoromethylhistidine, a suicide inhibitor of histidine decarboxylase, on histamine levels in the mouse tissues. Biochem. Pharmacol. 31, 2367-2370 (1982)

12 Lowry, O.H., Rosebrough, N.J., Farr, A.L. and Randall, R.J.: Protein measurement with the Folin phenol reagent. J. Biol. Chem. 193, 265275 (1951)

13 Garbarg, M., Barbin, G., Bischoff, S., Pollard, H. and Schwartz, J.C.: Dual localization of histamine in an ascending neuronal pathway and in nonneuronal cells evidenced by lesions in the lateral hypothalamic area. Brain Res. 106, 333-348 (1976)

14 Schayer, R.W. and Reilly, M.: Metabolism of ${ }^{14} \mathrm{C}$ histamine in brain. J. Pharmacol. Exp. Ther. 187, 34-39 (1973)

15 Hough, L.B. and Domino, E.F.: Tele-methylhistamine oxidation by type $B$ monoamine oxidase. J. Pharmacol. Exp. Ther. 208, 422-428 (1979) 